\title{
Using Lean Six Sigma to improve timeliness of clinical laboratory test results in a university hospital in Egypt
}

Islam Ibrahim

National Center for Health Information, Kuwait Ministry of Health, Safat, Kuwait, and Department of Biomedical Informatics and Medical Statistics, Alexandria University Medical Research Institute, Alexandria, Egypt

Magda Sultan

Department of Haematology, Alexandria University Medical Research Institute, Alexandria, Egypt

Omaima Gaber Yassine and Adel Zaki

Department of Biomedical Informatics and Medical Statistics, Alexandria

University Medical Research Institute, Alexandria, Egypt

Hossam Elamir

Quality and Accreditation Directorate, Kuwait Ministry of Health,

Safat, Kuwait, and

Wafaa Guirguis

Department of Health Administration and Behavioural Sciences, Alexandria University High Institute of Public Health, Alexandria, Egypt

\begin{abstract}
Purpose - Healthcare environments are highly complex and full of variation and inefficiency. However, variation and inefficiency can be measured and improved, providing better quality care at a lower cost. This study aims to report the application of Lean Six Sigma (LSS) in a haematology laboratory in a university hospital in Egypt.

Design/methodology/approach - The authors used case study research. Applying the define, measure, analyse, improve and control phases of the DMAIC methodology together with lean tools, the problem was identified, the process mapped, the causes analysed and improvements implemented.
\end{abstract}

(C) Islam Ibrahim, Magda Sultan, Omaima Gaber Yassine, Adel Zaki, Hossam Elamir and Wafaa Guirguis. Published by Emerald Publishing Limited. This article is published under the Creative Commons Attribution (CC BY 4.0) license. Anyone may reproduce, distribute, translate and create derivative works of this article (for both commercial and non-commercial purposes), subject to full attribution to the original publication and authors. The full terms of this license may be seen at http://creativecommons.org/licences/by/4.0/legalcode

The authors would also like to acknowledge the contribution of the Haematology laboratory staff at the at the Medical Research Institute Hospital. We would also like to acknowledge Dr. Eman Farrag for her help throughout the study, and Dr. Raghda Hassan for helping with data collection.
Received 4 August 2021 Revised 16 October 2021 Accepted 13 January 2022 
IJLSS

13,5

Findings - Results show that LSS can be successfully implemented in challenging public sector healthcare settings. Management commitment, generating and implementing ideas from frontline staff, using a variety of quality tools and previous LSS training were all key to success. This is evidence that the LSS methodology is adaptable to any process, people or place.

Originality/value - There are no publications on LSS implementation in health care in Egypt. This study demonstrates the successful use of LSS in a university hospital (public sector) in a developing country, sharing insight into the facilitators and barriers in a real context with others in the healthcare field.

Keywords Six Sigma, Lean, Turnaround time, Timeliness, Clinical laboratory, University hospital, Egypt, Healthcare

Paper type Case study

\section{Introduction}

Laboratories play a vital role in clinical decision-making in terms of diagnosis, prognosis and treatment. Laboratory results influence patient management pathways initiating or discontinuing other services, with patient safety and cost implications, such as hospitalization, surgery, medications or further investigations. A large US study on 72,196 patient encounters, found that $38 \%$ had laboratory tests ordered, compared to only $22 \%$ for radiology. This figure was higher for inpatients (98\%) than for emergency department $(56 \%)$ or outpatient encounters (29\%) (Ngo et al., 2017). Accordingly, quality in the clinical laboratory affects not only individual patient care but also the whole health system (Carlson et al., 2012).

Quality is about satisfying customer needs and expectations. Clinical laboratories have traditionally focused on internal indicators of analytical quality, whereas their main customers, physicians, are more keen on service quality; of which, timeliness is the key "satisfaction factor" (Kappelmayer and Tóth, 2016; Tsai et al., 2019). Laboratories customarily evaluate timeliness by measuring turnaround time (TAT), commonly defined as the time from receiving the specimen at the laboratory to availability of a validated result; or by calculating on-time percentages based on report-by times (Tsai et al., 2019). Globally, research has marked TAT as a chronic priority cause for physician dissatisfaction (Elhoseeny and Mohammad, 2013; Hailu et al., 2020; Jones et al., 2009; Novis and Dale, 2000). Shorter TAT increases patient benefit through earlier clinical decisions and reduced Length of Stay (LOS), ultimately improving physician and patient satisfaction, and saving cost (Kaushik et al., 2018; Tsai et al., 2019).

Six Sigma is a customer-focused, data-driven quality improvement (QI) methodology that seeks to reduce variation in processes that lead to defects (Stern, 2018). Traditional QI concepts are embedded within Six Sigma, but the additional structured methodology (define, measure, analyse, improve and control [DMAIC]) and sophisticated statistical tools make it a powerful approach for improving quality (Yaduvanshi and Sharma, 2017). Lean is a set of concepts, principles and tools used to create and deliver the most value from the customer's perspective while consuming the fewest resources and fully using the knowledge and skills of the people performing the work (Cohen, 2018). In Lean, value is defined from the customer's viewpoint. Value-added (VA) activities contribute to what the customer wants from a product or service, the rest is waste or non-value-added (NVA) activities (Cohen, 2018; Stern, 2018). Waste elimination is core to Lean methodology. Common types of waste include wasted human motion (such as unnecessary walking because of poor workplace ergonomics), waiting waste (especially common with batch-and-queue flow) and correction waste (for repairing defective products) (Cohen, 2018). Lean focuses on speed but is short on analytical tools for diagnosis and control, which are offered by Six Sigma's DMAIC framework. Therefore, combining both, Lean Six Sigma (LSS), is well suited for QI 
initiatives targeting timeliness (Yaduvanshi and Sharma, 2017). However, of all empirical research applying Lean and/or Six Sigma in healthcare, only $22 \%$ applied LSS (Henrique and Godinho Filho, 2020).

Because their work relies on testing and measurement, clinical laboratories are no strangers to statistical precision and quality control (Lippi and Plebani, 2018). This makes them potential candidates for LSS application. However, most applications have focused on the quality of internal testing rather than customer-focused service quality. Very few studies describe using LSS in the clinical laboratory (Henrique and Godinho Filho, 2020), and even fewer use it for improving timeliness. Two studies, from Turkey and the USA, report using LSS to improve timeliness in a laboratory with significant success (Hagg et al., 2007; Inal et al., 2018).

Egypt is a low/middle-income country (World Bank Group, 2021). Egypt's public healthcare providers include public universities, the Health Insurance Organization and the Ministry of Health and Population. Public health providers mainly serve the poorer sector of the population, which has increased in size lately. According to the World Bank, poverty in Egypt rose from 25.2\% in 2010, to 32.5\% in 2017-2018 (World Bank Group, 2020). This underscores the need for Egypt's public healthcare to adopt quality initiatives that improve its efficiency while reducing cost.

To date, no empirical studies have been published on implementing LSS in a healthcare organization in Egypt. Empirical research is based on real-world observations, and collects naturally occurring data, or experiment-based data, through field-based experiences rather than simulation (Vamsi Krishna Jasti and Kodali, 2014). One study in a private hospital in Egypt used Six Sigma and simulation to assess the different combinations of proposed improvement scenarios, without real-life implementation of these scenarios (Hussein et al., 2017). In this paper, we describe the application of LSS to improve the timeliness of routine Complete Blood Count $(\mathrm{CBC})$ test results in the haematology laboratory in a university hospital in Egypt.

\section{Lean Six Sigma in healthcare}

Today's healthcare environment is highly complex, costly and full of variations and inefficiencies. Ageing populations and technological advances have inevitably increased healthcare spending, forcing healthcare organizations towards better utilization of available resources with a focus on reducing waste and inefficiency (Koning et al., 2006; Watt et al., 2019). In 1998, two leading published articles advocated moving healthcare towards Six Sigma (Buck, 1998; Chassin, 1998). Chassin (1998) delivered three main messages: healthcare suffers serious quality problems, Six Sigma works for services as it does in manufacturing and it is time for Six Sigma to take off in healthcare. Some suggest that only a "near-death experience" can push organizations to truly adopt QI (Buck, 1998). For healthcare, this came with the 1999 Institute of Medicine (IOM, 2000) report, "To Err Is Human”. It brought the world's attention to the huge unnecessary injury, and loss of life attributed to medical errors while emphasising the concept of "good people working in bad systems." This report is widely credited with creating an interest in healthcare quality.

Quality has traditionally been viewed by healthcare professionals, through the transcendent approach of philosophy, as "innate excellence" that cannot be defined or measured (Garvin, 1984). For centuries, healthcare relied on individual physician expertise rather than an auditable, well-harmonized multi-professional system (Chassin, 1998). Research has identified physicians' professional dominance and autonomy in healthcare organizations as a cause of waste, variation and failure to implement QI changes (Gadolin, 2017). 
IJLSS

13,5

Despite their great success in the manufacturing industry, it has taken the healthcare sector much longer to adopt Lean and Six Sigma. This is sometimes called the "industrialization of healthcare" (Koning et al., 2006). The first empirical research article, i.e. one with field-based application, on Six Sigma in healthcare was published in 2004 by Heuvel et al. (2004); who described the implementation of multiple Six Sigma projects in a 384-bed hospital in the Netherlands. Since then, the number of published real-life applications of Six Sigma, and/or Lean in various clinical and non-clinical aspects of healthcare has increased, reaching 118 by 2017 (Henrique and Godinho Filho, 2020). These publications confirm the ability of Lean and Six Sigma to adapt to different healthcare environments, and significantly improve outcomes such as patient safety and satisfaction, timeliness, cost reduction and staff satisfaction among many others (Antony et al., 2018).

Despite the growing body of literature on Lean and Six Sigma applications in healthcare, some areas were less addressed than others. Six Sigma was only used in 37\% of reported applications, either alone or combined with Lean. Laboratories represented only $5 \%$ of the hospital areas in which any of the two QI methodologies were implemented. Until 2017, low/ middle-income countries contributed a mere $9 \%$ of applications, compared to $91 \%$ by highincome countries (Henrique and Godinho Filho, 2020).

\section{Research methodology}

We used the case study research strategy. Its suitability to real-life events has made it the most common approach in LSS research in healthcare (Henrique and Godinho Filho, 2020). Our study has all the three indications described by Yin (2018) that favour case study design research over other methods: our study is about the "Hows" and the "Whys," generating and implementing ideas relies on staff behaviour over which we have very little control, and the action taken in each DMAIC phase is based on the results of the previous one in contemporary fashion. We followed the DMAIC methodology (Stern, 2018) to define the problem and customer requirements, measure baseline performance of the current process, analyse the data to discover the causes of the problem, improve the process to remove causes of defects, and control the process to make sure defects do not recur.

The study setting is the haematology laboratory at the Medical Research Institute Hospital (MRIH); a public 305-bed hospital affiliated to Alexandria University, Egypt. It provides free/subsidised outpatient and inpatient services to Alexandria and neighbouring areas. Laboratory staff include haematologists and technicians. Haematologists are medical doctors who have clinical roles (manage haematology inpatients and outpatients) and laboratory roles (such as Microscopic Examination (ME), and bone marrow aspiration and biopsy)

Details of data collection and analysis are mentioned in each phase separately. Multiple tools and techniques were used including Pareto charts, flowcharts, Spaghetti diagram, control charts, brainstorming, fishbone diagrams, why-why analysis, and hypothesis testing.

\section{LSS application}

4.1 Define

4.1.1 Determining the focus of the study. A series of prioritization stages were done to focus on a feasible, well-identified process. The laboratory serves inpatients, outpatients, company contracts, MRI employees, and research purposes. Inpatient services were the most common $(69 \%)$, and the most easily tracked and controlled. Consequently, we decided to focus on inpatient services. 
4.1.2 Listening to the voice of the customers (VOC). Laboratory customers were categorized into internal (laboratory management and staff), and external (inpatient physicians and nurses). Laboratory management identified late routine morning test results as their main concern.

A simple questionnaire was administered to a convenience sample of $75 \%$ of inpatient resident physicians and $76 \%$ of nurses to rate satisfaction with laboratory services. Pareto analysis showed that two items (timeliness of test results and abnormal results notification) caused $79 \%$ of physicians' dissatisfaction, and $74 \%$ of nurses'. Timeliness of test results ranked first among both physicians $(42 \%)$ and nurses (39\%). This narrowed down the focus to: timeliness of inpatient test results.

4.1.3 Selecting the priority test for improvement. Retrospective data showed that among the numerous types of tests, CBC was the most frequent ( $62 \%$ of all tests). Accordingly, the focus of the study from this point onwards was: timeliness of inpatient $\mathrm{CBC}$ results. At the haematology laboratory, $\mathrm{CBC}$ tests refer to any $\mathrm{CBC}$ request that requires microscopic examination (ME). Intensive care and haematology inpatient samples were excluded as they follow a separate pathway for reporting.

4.1.4 Confirming the problem with data. Laboratory management defined a late $\mathrm{CBC}$ test as "one for which the result was not ready before 11:00 a.m. the following day". A simple random sample of $\mathrm{CBC}$ tests $(n=120)$ collected from the laboratory information system (LIS) for two months, showed that $22 \%$ of the results were late.

4.1.5 Determining process boundaries. Time of specimen registration on LIS upon receiving the specimen at the laboratory (registration time); and time of result verification on LIS (verification time) were selected as the process beginning and endpoints respectively.

\subsection{Measure}

4.2.1 Detailed inpatient complete blood count process. Using detailed interviews with laboratory staff and shadowing them, the physical workflow was studied and mapped on a detailed swimlane flowchart (Figure 1) and a spaghetti diagram (Figure 2). The unnecessary human motion (long walks, stairs), which is considered waste, in addition to the batch-andqueue processing indicated an un-Lean process. The process steps, at different locations, were:

- inpatient ward:

1. Inpatient physician requests $\mathrm{CBC}$ test on paper form.

2. Nurse delivers request to laboratory reception in early morning.

3. Two phlebotomists leave laboratory to ward to collect all blood samples only once/day.

- laboratory upper floor:

4. Returning with specimens, phlebotomists hand requests at laboratory reception for LIS registration and barcoding

5. Phlebotomists spread blood films (thin layer of blood on microscope slide) for all specimens.

6. Blood films and specimen tubes are labelled then transported in batches to lower floor.

- laboratory lower floor:

7. Blood films are stained using pre-prepared stains and left to dry. 


\section{IJLSS \\ 13,5}

\section{4}

Figure 1

The routine inpatient $\mathrm{CBC}$ process

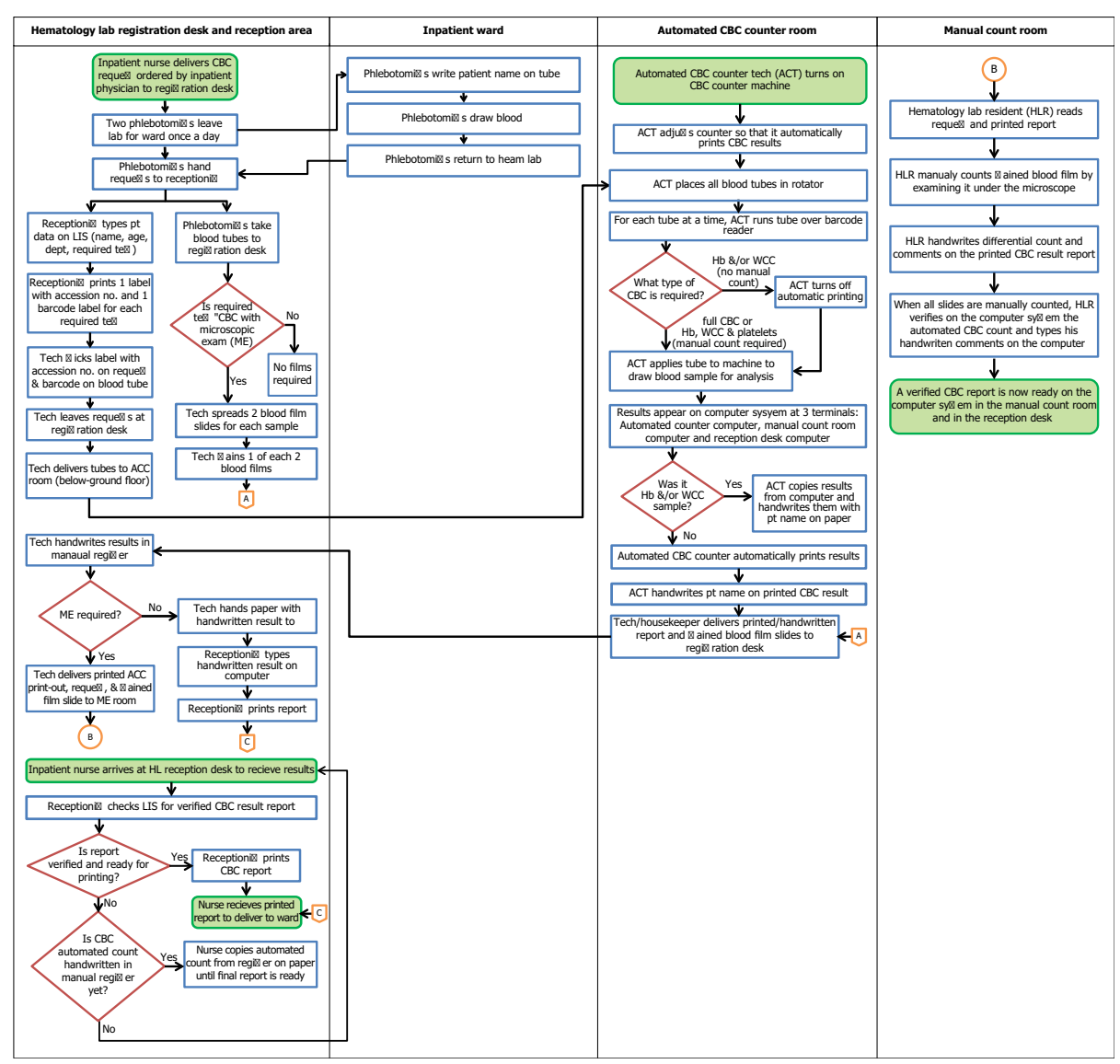

8. Specimens are analysed using haematology analyser producing automated cell count (ACC) results. Results of ACC analysis are printed from the analyser, and through network connection to LIS, also made available on computer terminals at $\mathrm{ME}$ room. The time each specimen is analysed (ACC time) is automatically recorded by the analyser.

- laboratory upper floor:

9. ACC print-outs and dry stained films are delivered to upper floor in batches. Results on ACC print-outs are handwritten into a manual register by technicians (for record-keeping) at the registration desk.

10. Each ACC print-out is matched to its dry stained film and stapled to its request.

11. These three matched items are delivered into ME room in batches of irregular size.

- laboratory ME room:

12. Using three microscopes, haematologists microscopically examine each blood film for differential cell count and morphology, then write findings on the accompanying ACC print-out. 


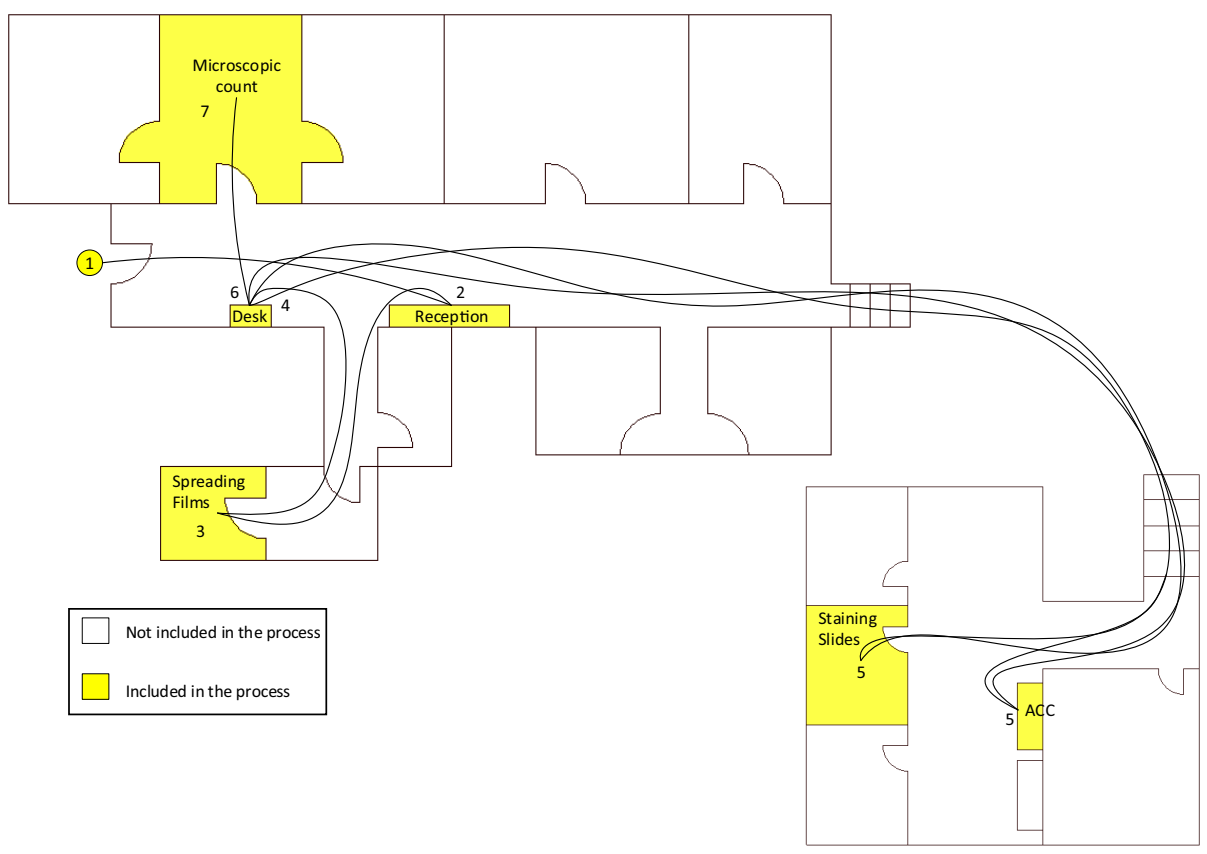

Lean Six Sigma

1165

13. After each haematologist finishes their share of films, they access LIS to add comments and modify ACC results according to ME to verify results. LIS automatically saves verification time. Only verified results can be printed.

- laboratory reception:

14. When inpatient nurse arrives at laboratory to collect results, technician/clerk at reception prints the report.

4.2.2 Distinguishing value-added steps. VA steps of the process were distinguished from NVA ones, and the duration of each VA step was measured to calculate the total VA time per $\mathrm{CBC}$ specimen.

4.2.3 Determining process milestones. Milestones mark the transition of a process from one phase to another. The $\mathrm{CBC}$ process in this study works in batches of unequal sizes. Three milestone times per $\mathrm{CBC}$ specimen are automatically recorded on LIS: specimen registration, specimen ACC analysis (called ACC time) and result verification. We also measured the time of delivery of the first batch of ME work (ACC print-outs matched to corresponding stained blood films and requests) into ME room. The end of the working day (time the last haematologist leaves work at ME room for the day was measured daily as it varied from day to day). The start of the working day is fixed (8:00 a.m.).

To analyse the process, we measured TAT for two phases: registration-to-ACC and ACCto-verification. The time outside working hours of the laboratory was excluded.

4.2.4 Identifying the $y$ 's. The main outcome metric was defined by laboratory management as the percentage of inpatient $\mathrm{CBC}$ s verified after 11:00 a.m. the day after registration.

However, from the main customers' perspective (inpatient physicians), test results were needed by $9: 10$ a.m. to allow the nurse to deliver the results before the morning daily round 
IJLSS

13,5

\section{6}

at 9:30 a.m. Therefore, another outcome metric was measured: $\mathrm{CBC}$ specimens verified after 9:10 a.m. the day after registration.

4.2.5 Brainstorming and organising possible causes. To delineate possible causes behind delayed inpatient $\mathrm{CBC}$ results, unstructured brainstorming sessions were held for haematologists and technicians. The causes were organized onto a fishbone diagram (Appendix 1) and translated into process metrics except for causes that were difficult to measure objectively (such as staff motivation or feelings).

4.2.6 Data collection. A measure information form was created for each metric, and data collection forms were designed. Data collection extended over 15 working days.

\subsection{Analyse}

During the data collection period, there were 476 inpatient $\mathrm{CBC}$ specimens

4.3.1 Outcome metrics. On a p-chart depicting $\mathrm{CBCs}$ verified after 11:00 a.m., the process was unstable with multiple special causes and an average of $19 \%$. The historical sigma level during that period was 2.4 sigma. The p-chart for $\mathrm{CBCs}$ verified after 9:10 a.m. was also unstable with an average of $65 \%$. The historical sigma level was 1.1 sigma. This highlights the importance of listening to the VOC. From laboratory management perspective, only $19 \%$ of results were unacceptable. However, from inpatient physicians' perspective, $65 \%$ were unacceptable.

4.3.2 Process phases. To determine which part of the process contributes most to the delay, we studied both phases of the process: registration-to-ACC and ACC-to-verification. The median daily registration-to-ACC TAT was stable with an average of $1.3 \mathrm{~h}$ (LCL-UCL $0.0-2.7 \mathrm{~h}$ ); the specification limit for this phase was $1.5 \mathrm{~h}$. The daily median ACC-toverification TAT was also stable with an average of $5.1 \mathrm{~h}$ (LCL-UCL $0.2-10.1 \mathrm{~h}$ ); the specification limit for this phase was $3.5 \mathrm{~h}$.

Process cycle efficiency (PCE) is the percentage of the process that is VA (George, 2010). Because the process works in batches, we calculated PCE as follows:

$$
\mathrm{PCE}=\frac{\text { (i.e., total VA time of one specimen } \mathrm{x} \text { number of specimens on that day) }}{\text { total TAT for all verified specimens on the same day }}
$$

The PCE of ACC-to-verification (Mdn 4\%; min-max 3-6\%) was significantly lower than that of registration-to-ACC (Mdn 37\%; min-max 15-55\%), $p<.001$. These results indicated that ACC-to-verification was a higher priority phase for improvement than registration-toACC. Further analysis will focus on possible factors affecting this phase.

\subsubsection{Results concerning the $x$ 's.}

- Diagnosis documentation: The requests of $25 \%$ of $\mathrm{CBCs}$ lacked diagnosis causing longer ME time.

- Unnecessary CBC workload: The results of $20 \%$ of all CBCs were not collected.

- Phlebotomy: The stable average duration of phlebotomy (from time phlebotomists left laboratory until time they returned with specimens) per phlebotomist was 60 $\pm 14 \mathrm{~min}$, i.e. within the acceptable $60 \mathrm{~min}$ set by laboratory management. There was no significant difference between the laboratory's three phlebotomists, $p>0.05$. Registration started within 10 min of phlebotomists' arrival $83 \%$ of the time.

- ACC analysis: The ACC machine malfunctioned (stopped working for a brief period and displayed error message) at least once daily (Mdn 9; max 20 times/day); all 
caused by network problems (LIS connection). On average, ACC analysis started 3.6 $\pm 1.4 \mathrm{~h}$ from the beginning of the working day.

- Delivery of first work batch into ME room: For haematologists to start ME, they need both ACC print-outs and dry stained films. The average time of delivery of the first batch of work into ME room was $3.5 \pm 0.5$ hours from the beginning of the working day. The median delay between the arrival of the first batch of both items (ACC print-outs and dry stained films) at the reception desk and their entry into the $\mathrm{ME}$ room was $44 \mathrm{~min}$. This unexplained delay was mainly attributed to manual registration of $\mathrm{ACC}$ results in the register.

- Interruption: The median daily number of interruptions (every time a person who is not part of the $\mathrm{CBC}$ process entered the $\mathrm{ME}$ room and spoke to any of the haematologists) was 60 (min-max 37-77), mostly patients and relatives.

- Microscopic examination: To estimate time spent on ME, we counted the number of haematologists sitting at the three microscopes at the start of each 15-min interval from the arrival of the first batch into the ME room, until the end of the day (which varied from day to day).

$$
\text { ME staff_minutes/hour }=15 \times 4 \times \text { number of haematologists }
$$

- Delay: During the first hour of arrival of the first batch, median ME staff-minutes was 45. The maximum possible, 180 staff-min $(15 \times 4 \times 3)$, was not reached on any day.

- Efficiency: The median daily total ME staff-minutes for all three haematologists was 300 (min-max 120-480), this extended over a median period of $3 \mathrm{~h} 30 \mathrm{~min}$ a day. The imaginary optimal scenario (if all three haematologists were working in all 15-min intervals starting from the arrival of the first batch) would produce the same ME minutes (equal to those measured daily) over a significantly shorter period (Mdn $1 \mathrm{~h} 45 \mathrm{~min}$ ), $p=0.001$.

- Haematologists' non-CBC workload: Total TAT was not correlated to the number of inpatients, outpatients or other laboratory tests (weights were assigned per type of test by its required workload), $p>0.05$.

- Blood film re-staining: Poorly-stained blood films that required re-staining (4\%) had significantly longer ACC-to-verification TAT $(\mathrm{Mdn}=13.5 \mathrm{~h})$ than those that didn't (Mdn 5.0 h), $p<0.001$.

- Late urgent $C B C$ requests: Thirteen urgent requests were sent by inpatient physicians after phlebotomists returned with the day's routine samples, forcing them to leave their scheduled work in the laboratory (phlebotomists also function as laboratory technicians staining films and other CBC-related tasks) and return to the ward for phlebotomy. Haematologists argued that these requests were not clinically urgent but no regulations exist for sending late urgent specimens.

- Other factors: During the study, no blood films or ACC print-outs were lost. Diluents were always available. There were no new haematologists and no complaints of absenteeism. Only two CBC requests were lost, and only three results were not verified on LIS. Scientific support was readily available by senior haematologists, yet administrative supervision of workflow was constantly missing.

4.3.4 Why-why analysis. The above results were communicated to laboratory staff, and the why-why technique was used to explore underlying causes. Inpatient physicians were asked about undocumented diagnoses on $\mathrm{CBC}$ requests and unclaimed $\mathrm{CBC}$ results. The results are summarised in Table 1 . A control-impact matrix was then constructed, root 


\section{IJLSS \\ 13,5}

Fact communicated to process owners

The "why" question

Root causes

In total, 20 blood films (4\%) were re-stained. ACC-toverification TAT was

1168

significantly longer for films that needed re-

staining $(\mathrm{Mdn}=13.5 \mathrm{~h})$

than those that did not

$(\mathrm{Mdn}=5.0 \mathrm{~h})$

Unexplained NVA time (after subtracting delivery time and time until arrival of dry stained films) between time of first inpatient ACC analysis and delivery of the first batch of ACC print-outs and films into the ME room after they arrive at the registration desk, median of $44 \mathrm{~min}$; ranging from 17 to $67 \mathrm{~min}$ All days had ACC malfunctions. (number of times it stopped working: Mdn 9; max 20 times/day)

During the first hour of arrival of the first batch of work into ME room, median ME staff-minutes was 45.

The maximum possible, 180 staff-min $(15 \times 4 \times 3)$, was not reached on any day ME minutes extend over a significantly longer time span daily than they need to. Actual median $3 \mathrm{~h}$, 30 min; optimal median $1 \mathrm{~h}, 45 \mathrm{~min}, p=0.001$
Why are films re-stained, and why do re-stained films take that long?

Why is there a delay in delivering first batch of work into ME room?

Why does ACC stop working?

Why doesn't ME start right away on arrival of ACC print-outs and dry stained films?

Why does ME take longer than it should?
Improper stain preparation and improper staining of blood films because technicians have poor staining skills and are unaware of value of goodquality staining. The re-staining process is unstandardized, with multiple handoffs causing delays especially when re-staining requests are forgotten or lost Manual registration step in which results of ACC analysis are handwritten into a register before delivery into ME room. Used as backup for LIS because staff don't trust LIS because of repeated network connection problems and software problems because of poor maintenance and lack of laboratory-assigned IT staff

- High room temperature because no air conditioner in ACC room - ACC-LIS network connection problems

- Poor maintenance because engineers do not come promptly when called because no IT staff assigned for laboratory

- Haematologists have other responsibilities in hematology department (inpatient, outpatient care, other hematology tests, bone marrow biopsy, residents attend postgraduate lectures). Their responsibilities are scheduled independent of ME work. So, tasks in different schedules overlap - Long time for ME per film because of missing diagnoses, poorly stained films or challenging ME findings so need to consult more senior haematologists - Discussions between haematologists because of lack of after-clinic meetings, so residents spend time that is assigned for ME in discussing inpatient and outpatient cases. Furthermore, there is no doctors' lounge and no specific time for lunch breaks

- Too many interruptions 
Fact communicated to process owners

The median number of interruptions per day was 60; ranging from 37 to 77

$25 \%$ of inpatient CBC requests lack patient diagnosis

$20 \%$ of verified inpatient $\mathrm{CBC}$ results were not collected

The "why" question

Root causes

Why are there too many interruptions at the $\mathrm{ME}$ room?
Why don't inpatient physicians document patient diagnoses?

Why do inpatient physicians order $\mathrm{CBC}$ s and not collect the results?
- Poor location of ME room: first door just beside the main entrance (even before reception desk; Appendix 1), and door open at all times so, visitors (patients/relatives) may enter ME room to ask about outpatient location or blood draws for outpatient tests or any other queries that should have been asked at the reception desk instead

- Room has two side doors (apart from the entrance) for senior haematologists who are also responsible for more complex inpatient cases. Postgraduate students also cross ME room to reach the senior haematologists in the side rooms.

- Patients and relatives enter room easily because: temporary outpatient clinic occupies a room inside the lab premises that opens onto same corridor because original clinic is being renovated

- No specific hematology ward so haematology inpatients occupy designated beds in other wards. Moreover, haematologist responsible for inpatients may also be on $\mathrm{ME}$ schedule, so hematology inpatient nurses may come down to consult with haematologist on inpatient care

- Inpatient physician may ask nurse to fill in the request because they are busy with too many patients

- Physicians unaware of relevance of diagnosis to $\mathrm{ME}$

- No regulations in place to oblige physicians to document diagnoses on laboratory requests

- Inpatient physician requests another $\mathrm{CBC}$ for the same patient because results of first test were late

- Patients discharged before CBC results were ready because of large number of patients to be admitted with insufficient number of beds

- $\mathrm{CBC}$ ordered (includes ME by default) while only ACC results needed (e.g. Hb or WCC). Nurse can copy ACC results from manual register located near reception desk and not come back for results of ME after verification
Lean Six Sigma

1169

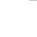


IJLSS

13,5

causes considered by the process owners to be of high or medium impact and high or medium control were set as targets for improvement (Appendix 2).

\subsection{Improve}

4.4.1 Brainstorming the remedies. Using brainstorming, laboratory staff themselves proposed process changes to address the root causes; therefore, changes for improvement were enthusiastically accepted and fully implemented. Whenever several solutions were proposed, alternatives were evaluated using a prioritization matrix to select the best one by staff themselves (Appendix 2). The remedies were planned, required tasks documented and individuals assigned per task. Support of senior leadership (laboratory and hospital) was ensured before implementation. Personnel at all levels of the $\mathrm{CBC}$ process were involved in implementation: haematologists and technicians, inpatient residents and nurses. Over a period of one month, the improvements were implemented one at a time. When all improvement changes were piloted and fully implemented, data collection for evaluating the process after improvement started.

4.4.2 Implementing the remedies. The remedies (improvement changes made to the process) were:

- To avoid ACC malfunction: Analyse phase results further supported previous plans before the study to replace the ACC machine because of ACC-LIS connection problems. Therefore, the ACC machine was replaced with an upgraded version, and an air-conditioner fitted in the room. IT personnel were involved to resolve network problems related to LIS connection.

- To reduce interruption: A housekeeper was assigned at the main entrance to assist patient flow in the right direction away from the ME room. Based on the results, laboratory management hastened the undergoing renovations of the haematology department outpatient clinic. Outpatient services returned to the original location outside the laboratory. Specified time was allocated after clinic hours for patients and relatives to meet haematologists in charge of inpatients and outpatients according to a set schedule and were printed on posters outside the main entrance.

- To improve diagnosis documentation: Inpatient residents were made aware, through meetings and posters, of the importance of documenting diagnoses for minimizing $\mathrm{ME}$ time and were informed that requests without a diagnosis would not be processed.

- To reduce unnecessary ME workload: Meetings were conducted with inpatient physicians to explain the difference, in effort and time, between a $\mathrm{CBC}$ that requires $\mathrm{ME}$ and one that does not. $\mathrm{A} \mathrm{CBC}$ request without further specification means $\mathrm{ME}$ is done by default. Certain specified requests (as platelet count) also require ME. However, if only ACC results are required (for example haemoglobin or white blood cell count), then no ME is needed. Inpatient physicians agreed that a full $\mathrm{CBC}$ will only be requested if ME results are needed. If only ACC analysis is needed, then this should be specified in the request instead of writing "CBC." In case both are needed (preliminary early ACC results, as well as $\mathrm{CBC}$ with $\mathrm{ME}$ ), both must be written on the request separately. In this case, the laboratory will provide two results: ACC result by 1:00 p.m. the same day, and $\mathrm{CBC}$ with $\mathrm{ME}$ results the following day by 11:00 a.m.

- To organize time spent on ME: Haematologists distributed ME in equal shares in a detailed work schedule that avoids overlap between ME work and other responsibilities. 
- To reduce blood film re-staining: A training workshop was conducted to improve the skills of laboratory technicians on both stain preparation and blood film staining.

- Standardising the re-staining process: In the old process, to request film re-staining, a haematologist gave the ACC print-out with a written paper request to re-stain to the closest available technician (may not be the one assigned for staining that day). As technicians are busy with other tasks, requests may be forgotten until accidentally discovered on the desk, or worse, when a nurse requests the result and the result is not available triggering a search for the film. A new standardised process was designed by the staff themselves and effectively communicated to all involved. The process included a step in which every time a film required restaining, the haematologist would document it on a table on the wall beside the desk where technicians work (just outside ME room), and this ensured that none were forgotten. It also motivated technicians giving them personal pride and competition among themselves to have the fewest number of re-stained films.

- Standardising late urgent inpatient $C B C$ request process: Phlebotomists collect blood samples from inpatient wards only once daily at 9:10 a.m. Later requests disrupt daily routine work at the laboratory, as phlebotomists have other commitments in the laboratory functioning also as laboratory technicians. Haematologists worked with inpatient physicians to standardise the urgently-needed late request process (Appendix 3).

- Eliminating the manual registration step: Manual registration is a NVA step, delaying entry of the first batch for ME. It includes copying (handwriting) results from ACC print-out into a register for record keeping because of fears of any network or LIS problems. Laboratory staff decided to print a worklist by the ACC machine for all specimens analysed per day to be stored in a folder kept in the ACC room instead of at the registration desk as was the case before.

4.4.3 Results after improvement. During 12 working days of data collection, there were 374 routine inpatient $\mathrm{CBC}$ s requiring $\mathrm{ME}$.

4.4.3.1 Outcome metrics.

- CBCs verified after 11:00 a.m. the following morning: only 1\% were verified late, compared to $19 \%$ in the measure phase, $p<0.001$. The p-chart showed a shift in the desired direction, with all 12 points below the centreline, signalling the beginning of a new stable process with only common cause variation and a centreline of $1 \%$ (Figure 3). Sigma level improved from 2.4 in measure phase to 3.7.

- $\quad \mathrm{CBC}$ verified after 9:10 a.m. the following morning showed a significant decrease $(40 \%)$ compared to the measure phase $(65 \%), p<0.001$. However, the p-chart remained unstable with no special cause shift in the desired direction. Process sigma level for this metric increased to 1.8 from 1.1 in the measure phase. Both are historical sigma levels as the process was unstable during both phases for this metric and cannot be used for future prediction.

\subsubsection{Other metrics.}

- ACC analysis: The new ACC machine worked without malfunction, and there were no ACC-LIS network problems. ACC analysis was performed significantly earlier from the beginning of the working day $(3.1 \pm 0.6 \mathrm{~h})$ compared to the measure phase $(3.6 \pm 1.4 \mathrm{~h}), p<0.001$. 


\section{IJLSS}

13,5

1172

Figure 3.

The main outcome metric before and after improvement

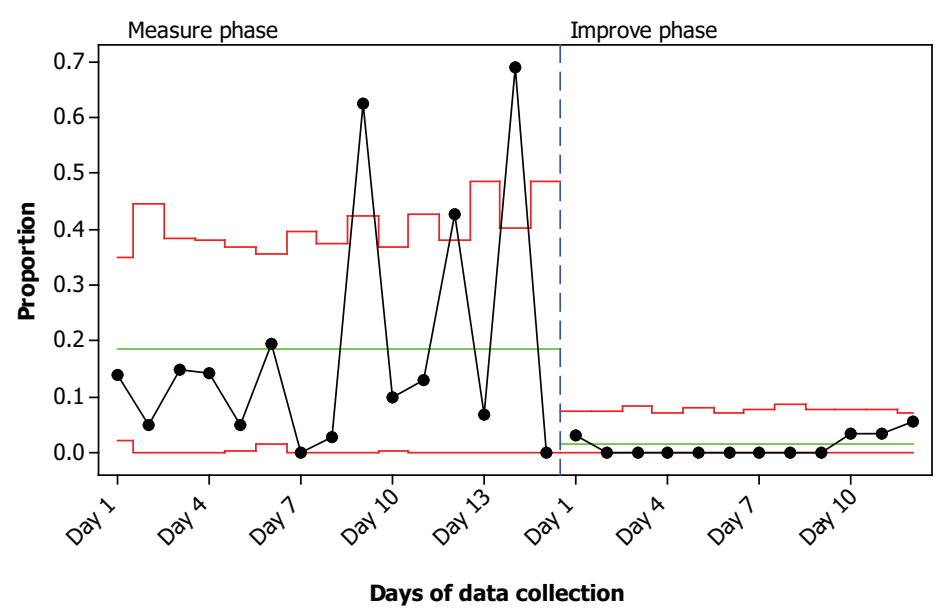

- Time of delivery of first batch of work into ME room was significantly shortened to $3.1 \pm 0.4 \mathrm{~h}$, compared to $3.5 \pm 0.5 \mathrm{~h}$ in the measure phase, $p=0.017$.

- Interruptions: During the measure phase, it was important to objectively measure interruption. However, this was a tedious task and required dedicated staff for data collection. In the improve phase, we asked haematologists to rate interruptions daily as (much improved, improved, the same, worse and much worse) relative to the situation before implementing the remedies. On all days, the rating was much improved or improved.

- Blood film staining: Haematologists were asked to rate daily the quality of film staining relative to that before improvement. During the first two days, staining was rated as improved, then "the same" for three days, then "much improved" for the remaining seven days. In the measure phase, all re-stained films $(n=20)$ were verified after 11:00 a.m. the following day, whereas in the improve phase, only five of the 15 re-stained films were, $p<0.001$. The proportion of re-stained films in the improve phase was not significantly lower than in the measure phase, $p>0.05$. This may be because before improvement, haematologists chose to spend longer time examining poorly stained films rather than requesting re-staining because of lack of trust in the re-staining process. In contrast, during the improve phase, it was easier to request a re-stain because the process was standardised and quicker, films were of better quality and no re-staining requests or films were lost.

\subsection{Control}

Improve phase results were shared with laboratory staff. Documentation of methods and results of previous phases, and newly standardised processes was handed off to the process owners. Effectively communicating these documents ensures that activities are performed consistently over time. Because the remedies were developed by those who do the work, the resulting "sense of ownership" is likely to support compliance and control.

A control plan was created with the process owners to sustain the accomplished gains (Appendix 4). Control variables, specification limits and actions taken to address out-ofcontrol results were selected by laboratory staff, keeping in mind feasibility of measurement 
and analysis by staff and being under laboratory control. Process audit checklists were prepared for the newly standardised processes (re-staining and late urgent $\mathrm{CBC}$ requests) to evaluate these processes at regular intervals. To monitor customer satisfaction (inpatient physicians and nurses), it was agreed that a simple satisfaction survey rating laboratory services would be conducted every six months.

\section{Discussion}

The LSS DMAIC methodology succeeded in improving the timeliness of routine $\mathrm{CBC}$ results in the haematology laboratory in MRIH. This demonstrates the ability of this wellstructured methodology to adapt to different settings, resources and personnel including public healthcare facilities in low-/middle-income countries.

\subsection{Success factors}

The motivation shown by laboratory staff was remarkable. LSS is based on process frontline staff solving their problems under cover of a disciplined well-structured methodology. In this study, laboratory staff diagnosed their own process problems and created, planned and implemented their own improvement changes. This guaranteed their full involvement and support. By the end of the project, staff, most notably laboratory technicians, felt empowered and expressed pride in the improvement gained by the changes they designed and implemented. This corroborates findings from a Swedish study on response to change in healthcare, which concluded that healthcare professionals tended to be more involved or support changes, which they either initiated themselves or featured their active input (Nilsen et al., 2019).

Hospital and laboratory management support and commitment also motivated staff. Laboratory management took a minor role when it came to technical details, empowering frontline staff to build on their in-depth understanding and experience with the process. On day one, laboratory management reassured staff that it is because of bad processes, rather than bad people, that the laboratory needs improvement (IOM, 2000). Throughout the study, there was a focus on widespread engagement of frontline staff, individual and collective ownership of both process and results, encouragement of creativity and optimism regarding success. This contrasted the often negative response from people when handed a new topdown vision for an organization in which their involvement and ideas were never sought (Zakariasen and Henderson, 2010). Moreover, leadership support was essential for permissions and resources needed for implementing the remedies in the laboratory as well as ensuring inter-departmental collaboration with inpatient physicians and nurses. A study in 47 US-based hospitals also listed leadership support as the number one facilitator of successful interdepartmental QI (Leyenaar et al., 2019).

There were several reasons behind leadership support and staff motivation. Firstly, the seriousness of the problem to be resolved. As inpatient physicians and nurses are the main laboratory customers, their dissatisfaction with timeliness of test results was quite a concern for the laboratory. Secondly, the quality culture already present because of an ongoing accreditation process, had brought about quality awareness and paved the way for adopting LSS. Thirdly, the provision of data-backed facts by the researcher throughout the study, gained the trust and support needed from laboratory management and staff. Lastly, the work was orchestrated by the lead author, a physician with statistics qualification and a SS Green Belt, who worked in the same institute. Familiarity with the work environment and culture, understanding the uniqueness of healthcare settings and the mind-set of its people, enabled better communication, facilitating success. Cohen (2018) mentions using consultants from manufacturing, with insufficient understanding of the complexity of healthcare 
IJLSS

13,5

services, as an issue with QI applications in healthcare. Heuvel et al. (2004) who conducted the first empirical study of Six Sigma in healthcare, also used Green Belts, staff from the same hospital who received Green Belt training, to perform the projects.

Laboratory staff, and at times inpatient physicians and nurses, were encouraged to work together as a team. Their collaboration strengthened and communication improved as work advanced through the DMAIC phases. Thinking about creative ways to solve their problems together, and sharing their ideas aloud, contributed to the success of the study. This highlights the importance of teamwork in healthcare settings. A study that combined teamwork training with Lean concepts as an intervention in the UK orthopaedic hospital, reported significantly better patient safety outcome measures (Robertson et al., 2015). Teamwork, trust and staff satisfaction are sometimes used as indicators of success in the course of a LSS project until quantifiable results of improvement are realised at the end. Gayed et al. (2013) used this "soft-data" approach in their LSS project to reduce the LOS for patients undergoing knee replacement surgery in the US hospital.

Standardisation, a Lean tool, was used to improve processes, such as film re-staining, significantly improving the timeliness of results for re-stained films. This is in accordance with other Lean and/or Six Sigma healthcare applications, in which standardisation was the second most commonly used quality tool (Henrique and Godinho Filho, 2020). Standardisation enabled us to create audit checklists for the control phase as vital process steps became easy to track. The power of checklists in promoting adherence to recommended practice has been demonstrated over and over in healthcare's complex and demanding environment. One example is a study that used Lean principles, including standardisation and a checklist, to improve delays in discharges from inpatient units (Beck and Gosik, 2015).

\subsection{Challenges}

A large number of $x$ 's were identified during the measure phase for which data was unavailable, necessitating tedious data collection and, at times, around-the-clock observation. Availability of data is the number one challenge reported in published Six Sigma applications in healthcare, irrespective of the country of implementation (Antony et al., 2018).

Brainstorming sessions were held separately for haematologists, and technicians, as requested by laboratory staff who feared that status barriers to communication, would jeopardize the flow of ideas. This allowed technicians to share their perspective on the process freely, unthreatened by physicians' (haematologists') relative dominance that is common in multi-professional teams in healthcare (Gadolin, 2017). Status-based communication is more common in healthcare situations where superior-subordinate relationships exist (such as between physicians and nurses) than team-based communication, often hindering QI changes (Matzke et al., 2014). During sessions, each party blamed the other for the delay, creating an unnecessarily large number of $x$ 's. However, as we advanced through the DMAIC phases, team dynamics improved, blame throwing decreased and staff became more objective and data-oriented.

Inpatient physicians blamed late results on laboratory staff, not considering themselves as part of the problem. This caused resistance to change by some inpatient physicians, who doubted that changing their practice with respect to the proposed remedies (such as documenting diagnoses on requests) would indeed improve timeliness. A literature review of Six Sigma applications in healthcare between 1998 and 2016, listed resistance to change and cultural issues among the vital few challenges facing implementation (Antony et al., 2018). To minimize resistance, we provided data-backed facts behind each of the proposed 
remedies; this proved to be successful. This corroborates findings from Heuvel et al.'s (2005) study. They also observed that data-based facts proved to be strong arguments to overcome resistance to change and convince medical specialists to change their method of working. This also confirms results by Nilsen et al. (2019) that health staff show less resistance and offer more support to solutions that are founded on facts and are well communicated.

Because of scheduling limitations, we were unable to conduct brainstorming sessions that engage as many staff as possible at the same time. We opted instead for "mini" sessions, with a few participants at a time at their convenience. This is a general problem in healthcare. According to Zakariasen and Henderson (2010), the use of short time-limited sessions focusing intensely on one topic (rapid-cycle brainstorming), not only encourages and holds the participants' interest and enthusiasm but also generates a rapid flow of ideas. This is in accordance with our observations.

\subsection{Selected outcome metrics}

Timeliness of test results was the main cause of dissatisfaction among inpatient physicians and nurses in define phase. This is in accordance with studies that surveyed levels of physician satisfaction with hospital laboratory services in different countries (Elhoseeny and Mohammad, 2013; Hailu et al., 2020; Jones et al., 2009; Novis and Dale, 2000).

Timeliness can be measured by TAT (expressed in minutes or hours) or reporting compliance to a desired specification limit (expressed as a percentage). TAT evaluates the process by which the service is generated, whereas reporting compliance evaluates a desired outcome of that service. In addition to being customer-focused, easier data collection (yes/no) favoured using compliance over TAT as the main outcome metric in this study. This facilitated data reporting to laboratory staff in an understandable way throughout all DMAIC phases and increased the likelihood of compliance to continue monitoring the main outcome metric in the control phase. Howanitz (2005), who published extensively on laboratory medicine surveys, also recommends that TAT goals be expressed as a percentage of all results completed within the time interval.

It is common practice for clinical laboratories to establish their own report-by times. In our study, laboratory management selected 11:00 a.m. the following morning as their reportby time for routine inpatient $\mathrm{CBCs}$. Defects (non-conforming) tests were those verified later than 11:00 a.m. In a college of American pathologists (CAP) study on morning rounds inpatient test availability of 79,860 morning CBC results in 367 institutions, each participating institution was asked to establish a time by which they expected to release their routine test results in non-intensive patient care. The report-by times selected by different laboratories were as early as midnight and as late as after 10 a.m. the following morning. The CAP study found that $90 \%$ of inpatient morning routine $\mathrm{CBC}$ s were reported by the reporting deadline (Novis and Dale, 2000). Their value was higher than that reported during our measure phase $(82 \%)$. However, during the improve phase, the percentage of tests reported by 11 a.m. jumped to $99 \%$, which is higher than that reported by the CAP study.

Physicians, laboratories' main customers, care less about how long it takes to generate test results, than about having them ready when they need to make patient management decisions (Tsai et al., 2019). Inpatient physicians selected a report-by time of 9:10 a.m. at the laboratory to allow nurses to deliver results before their morning daily round at 9:30 a.m. The compliance rate by laboratory standards (ready by 11:00 a.m.) in the measure phase was $82 \%$, whereas that by inpatient physicians standards (ready by 9:10 a.m.) was much lower at $35 \%$, reaching $60 \%$ after improvement. However, this was still below the $87 \%$ reported by the CAP study as the percentage of clinicians who stated that the laboratory 
IJLSS

13,5

meets clinicians' needs of early morning test results (Novis and Dale, 2000). The discrepancy in report-by times between inpatient physicians and laboratory management explains customer dissatisfaction, highlighting the need to listen to the VOC and adopt the pragmatic approach, which recognizes the importance of TAT to clinicians when setting local TAT goals and report-by times (Hawkins, 2007).

\section{6}

\subsection{Strengths and practice implications}

This is the first published example of applying LSS in a university hospital in Egypt. This experience was the product of a collaboration of frontline laboratory staff, hospital and laboratory management and academic staff with experience in statistics, healthcare quality and clinical laboratory medicine affiliated to the same institute. Moreover, involving inpatient physicians and nurses and sharing the improvement results in MRIH helped transfer quality culture and awareness from the laboratory, where it is more common, to the ward where it is not. This represents an opportunity to start an organizational learning process that should facilitate future QI initiatives at MRIH based on an understanding of what worked or did not work and encourage further research applying LSS in more challenging ward environments with direct patient-healthcare worker interaction.

Three other low/middle-income countries from the Middle East reported Lean, Six Sigma or LSS application in healthcare; Lebanon, Iran and Jordan. In Lebanon, El-Eid et al. (2015) used Six Sigma to improve the patient discharge process in a university hospital. In Iran, Gheysari et al. (2016) implemented Six Sigma in a university hospital to reduce the number of cancelled surgeries. From Jordan, Al-Qatawneh et al. (2019), implemented Six Sigma to improve healthcare logistics in a private hospital, and El-Banna (2013) used it to improve patient discharge time in a public hospital. All studies resulted in significant improvement; however, none of them discussed the success factors or challenges facing implementation in their settings. Sharing results from our study, not only on the improvement of outcome metrics but also on the lessons learned, and the interaction of the healthcare professionals, who took part in or were affected by the applications, could be very helpful for future implementation in countries with comparable cultural and economic backgrounds.

Expected short term implications of this study include a possible reduction in inpatient LOS because of earlier diagnosis and treatment. Expected long term implications include improved inpatient physician and nurse satisfaction with laboratory performance; improved trust in laboratory test timeliness, potentially reducing repeated unnecessary test orders caused by delayed results of previously requested tests; and wider spread of quality culture in MRIH.

\subsection{Limitations}

The main limitation of this study is inability to generalize its process modifications to other settings. Hence, it is not the process-specific changes unique to the MRIH CBC process that can be adopted by others who aspire to implement LSS in other healthcare settings. It is rather the methodology itself, with its phases and tools and the lessons learned, in terms of success factors and challenges.

This study lasted around nine months, longer than a typical LSS project. Many times, other tasks took precedent for the laboratory and the team working on the project, delaying the start of the following Six Sigma phase.

Estimating the financial burden of late tests, and financial gain from improvement were beyond the scope of this study because as a university hospital funded by annual budget providing free healthcare to patients, the financial aspect was not of concern to the direct process owners. Further research is recommended to estimate measurable quantifiable 
financial returns brought about by this LSS implementation. Translating this improvement into money could encourage decision-makers to fund more LSS initiatives to improve the quality of services in other hospitals.

\section{Conclusion}

This study demonstrated the use of LSS to successfully improve the timeliness of inpatient routine $\mathrm{CBC}$ tests, the primary cause of customer dissatisfaction, at the haematology laboratory at MRIH. Results of the improve phase show that only $1 \%$ of inpatient routine $\mathrm{CBC}$ s were verified later than the desired target compared to $19 \%$ in the measure phase. Sigma level improved from 2.4 to 3.7. Laboratory management support and commitment, generating and implementing ideas by frontline staff, and previous LSS training were all key to success. The process changes used to effect improvement tended to be simple, and specific to the current unique process, people and place. However, the principles and tools used are universal, customizable and can hence be used in any other set of processes, people and place.

\section{References}

Al-Qatawneh, L., Abdallah, A.A.A. and Zalloum, S.S.Z. (2019), "Six sigma application in healthcare logistics: a framework and a case study", Journal of Healthcare Engineering, Vol. 2019, pp. 1-12.

Antony, J., Palsuk, P., Gupta, S., Mishra, D. and Barach, P. (2018), "Six sigma in healthcare: a systematic review of the literature", International Journal of Quality and Reliability Management, Vol. 35 No. 5, pp. 1075-1092.

Beck, M.J. and Gosik, K. (2015), "Redesigning an inpatient pediatric service using lean to improve throughput efficiency: inpatient pediatric service redesign", Journal of Hospital Medicine, Vol. 10 No. 4, pp. 220-227.

Buck, C.R. (1998), "Health care through a six sigma lens", The Milbank Quarterly, Vol. 76 No. 4, pp. $749-753$.

Carlson, R.O., Amirahmadi, F. and Hernandez, J.S. (2012), "A primer on the cost of quality for improvement of laboratory and pathology specimen processes", American Journal of Clinical Pathology, Vol. 138 No. 3, pp. 347-354.

Chassin, M.R. (1998), "Is healthcare ready for six sigma quality?", The Milbank Quarterly, Vol. 76 No. 4, pp. 565-591.

Cohen, R.I. (2018), “Lean methodology in healthcare”, Chest, Vol. 154 No. 6, pp. 1448-1454.

El-Banna, M. (2013), "Patient discharge time improvement by using the six sigma approach: a case study”, Quality Engineering, Vol. 25 No. 4, pp. 401-417.

El-Eid, G.R., Kaddoum, R., Tamim, H. and Hitti, E.A. (2015), "Improving hospital discharge time: a successful implementation of six sigma methodology”, Medicine, Vol. 94 No. 12, pp. e633.

Elhoseeny, T.A. and Mohammad, E.K. (2013), "Quality of the clinical laboratory department in a specialized hospital in alexandria, Egypt”, Eastern Mediterranean Health Journal, Vol. 19 No. 1, pp. 81-87.

Gadolin, C. (2017), "The logics of Healthcare - in quality improvement work", Doctoral dissertation, University of Gothenburg, Gothenburg, Sweden.

Garvin, D.A. (1984), "What does” product quality" really mean?”, Sloan Management Review (Pre1986), Vol. 26 No. 1, pp. 25-43.

Gayed, B., Black, S., Daggy, J. and Munshi, I.A. (2013), "Redesigning a joint replacement program using lean six sigma in a veterans affairs hospital”, JAMA Surgery, Vol. 148 No. 11, pp. 1050-1056. 
IJLSS

13,5

George, M.O. (2010), The Lean Six Sigma Guide to Doing More with Less: Cut Costs, Reduce Waste, and Lower Your Overhead, John Wiley and Sons, Hoboken, NJ.

Gheysari, E., Yousefi, H., Soleymani, H. and Mojdeh, S. (2016), "Effect of six sigma program on the number of surgeries cancellation”, Iranian Journal of Nursing and Midwifery Research, Vol. 21 No. 2, p. 191.

Hagg, H., Scachitti, S., Mapa, L., Brandford, L., Vanni, C. and Cox, C. (2007), Application of Lean Six Sigma Techniques to Optimize Hospital Laboratory Emergency Department Turnaround Time across a Multi-Hospital System, RCHE Publications, No. 30, p. 15.

Hailu, H.A., Yalew, A., Desale, A., Asrat, H., Kebede, S., Dejene, D., Abebe, H., et al. (2020), "Physicians' satisfaction with clinical laboratory services at public hospitals in Ethiopia: a national survey", Plos One, Vol. 15 No. 4, p. e0232178.

Hawkins, R.C. (2007), "Laboratory turnaround time”, The Clinical Biochemist Reviews, Vol. 28 No. 4, pp. 179-194.

Henrique, D.B. and Godinho Filho, M. (2020), "A systematic literature review of empirical research in lean and six sigma in healthcare", Total Quality Management and Business Excellence, Vol. 31 Nos 3/4, pp. 429-449.

Heuvel, J. V D., Does, R.J.M.M. and Vermaat, M.B. (Thijs). (2004), "Six sigma in a Dutch hospital: does it work in the nursing department?", Quality and Reliability Engineering International, Vol. 20 No. 5, pp. 419-426.

Heuvel, J. V D., Does, R.J.M.M. and Verver, J.P.S. (2005), "Six sigma in healthcare: lessons learned from a hospital", International Journal of Six Sigma and Competitive Advantage, Vol. 1 No. 4, pp. 380-388.

Howanitz, P.J. (2005), "Errors in laboratory medicine: Practical lessons to improve patient safety", Archives of Pathology and Laboratory Medicine, Vol. 129 No. 10, pp. 1252-1261.

Hussein, N.A., Abdelmaguid, T.F., Tawfik, B.S. and Ahmed, N.G.S. (2017), "Mitigating overcrowding in emergency departments using six sigma and simulation: a case study in Egypt", Operations Research for Health Care, Vol. 15, pp. 1-12.

Inal, T.C., Ozturk, O.G., Kibar, F., Cetiner, S., Matyar, S., Daglioglu, G. and Yaman, A. (2018), "Lean six sigma methodologies improve clinical laboratory efficiency and reduce turnaround times", Journal of Clinical Laboratory Analysis, Vol. 32 No. 1, p. e22180.

IOM (2000), "To err is human: Building a safer health system”, in Kohn, L.T., Corrigan, J.M. and Donaldson, M.S. (Eds), The National Academy Press, Washington, DC, available at: www.nap. edu/openbook.php?record_id=9728.

Jones, B.A., Bekeris, L.G., Nakhleh, R.E., Walsh, M.K. and Valenstein, P.N. (2009), "Physician satisfaction with clinical laboratory services: a College of American pathologists Q-Probes study of 138 institutions", Archives of Pathology and Laboratory Medicine, Vol. 133 No. 1, pp. 38-43.

Kappelmayer, J. and Tóth, J. (2016), "Clinical laboratories - production factories or specialized diagnostic centers", The Journal of the International Federation of Clinical Chemistry and Laboratory Medicine, Vol. 27 No. 2, pp. 156-165.

Kaushik, N., Khangulov, V.S., O'Hara, M. and Arnaout, R. (2018), "Reduction in laboratory turnaround time decreases emergency room length of stay", Open Access Emergency Medicine, Vol. 10, pp. 37-45.

Koning, H. D., Verver, J.P.S., Heuvel, J., van den, Bisgaard, S. and Does, R.J.M.M. (2006), “Lean six sigma in healthcare", Journal for Healthcare Quality, Vol. 28 No. 2, pp. 4-11.

Leyenaar, J.K., Andrews, C.B., Tyksinski, E.R., Biondi, E., Parikh, K. and Ralston, S. (2019), "Facilitators of interdepartmental quality improvement: a mixed-methods analysis of a collaborative to improve pediatric community-acquired pneumonia management", BMJ Quality and Safety, Vol. 28 No. 3, pp. 215-222. 
Lippi, G. and Plebani, M. (2018), "A Six-Sigma approach for comparing diagnostic errors in healthcare where does laboratory medicine stand?", Annals of Translational Medicine, Vol. 6 No. 10, pp. $12-12$.

Matzke, B., Houston, S., Fischer, U. and Bradshaw, M.J. (2014), "Using a team-centered approach to evaluate effectiveness of nurse-physician communications", Journal of Obstetric, Gynecologic and Neonatal Nursing, Vol. 43 No. 6, pp. 684-694.

Ngo, A., Gandhi, P. and Miller, W.G. (2017), "Frequency that laboratory tests influence medical decisions", The Journal of Applied Laboratory Medicine, Vol. 1 No. 4, pp. 410-414.

Nilsen, P., Schildmeijer, K., Ericsson, C., Seing, I. and Birken, S. (2019), "Implementation of change in healthcare in Sweden: a qualitative study of professionals' change responses", Implementation Science, Vol. 14 No. 1, p. 51.

Novis, D.A. and Dale, J.C. (2000), "Morning rounds inpatient test availability", Archives of Pathology and Laboratory Medicine, Vol. 124 No. 4, pp. 499-503.

Robertson, E., Morgan, L., New, S., Pickering, S., Hadi, M., Collins, G., Rivero Arias, O., et al. (2015), "Quality improvement in surgery combining lean improvement methods with teamwork training: a controlled before-after study", Plos One, Vol. 10 No. 9, p. e0138490.

Stern, T.V. (2018), Lean Six Sigma: International Standards and Global Guidelines, 2nd ed., Taylor and Francis Group, Boca Raton, FL.

Tsai, E.R., Tintu, A.N., Demirtas, D., Boucherie, R.J., de Jonge, R. and de Rijke, Y.B. (2019), "A critical review of laboratory performance indicators", Critical Reviews in Clinical Laboratory Sciences, Vol. 56 No. 7, pp. 458-471.

Vamsi Krishna Jasti, N. and Kodali, R. (2014), "A literature review of empirical research methodology in lean manufacturing", International Journal of Operations and Production Management, Vol. 34 No. 8, pp. 1080-1122.

Watt, T., Charlesworth, A. and Gershlick, B. (2019), "Health and care spending and its value, past, present and future", Future Healthcare Journal, Vol. 6 No. 2, pp. 99-105.

World Bank Group (2020), Arab Republic of Egypt: Poverty and Equity Brief, World Bank Group, Washington, DC, p. 2.

World Bank Group (2021), "Country classification”, World Bank Country and Lending Groups, available at: https://datahelpdesk.worldbank.org/knowledgebase/articles/906519-world-bankcountry-and-lending-groups (accessed 1 August 2021).

Yaduvanshi, D. and Sharma, A. (2017), "Lean six sigma in health operations: challenges and opportunities - 'nirvana for operational efficiency in hospitals in a resource limited settings", Journal of Health Management, Vol. 19 No. 2, pp. 203-213.

Yin, R.K. (2018), Case Study Research and Applications: Design and Methods, 6th ed., SAGE Publications, Los Angeles, CA.

Zakariasen, K. and Henderson, I. (2010), "Rapid-cycle brainstorming: facilitating whole-systems change in time- and scheduling-challenged healthcare settings", Journal of Healthcare Leadership, Vol. 2010 No. 2, pp. 97-111. 
Figure A1.

Fishbone diagram
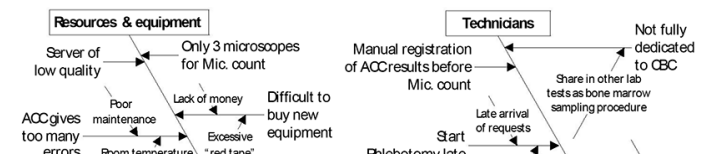

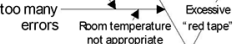
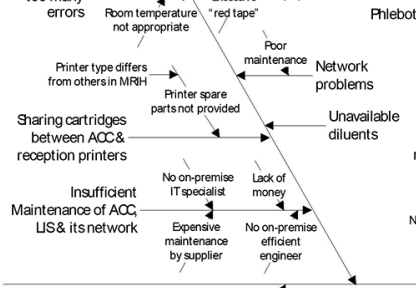

ts

motivated Poorly trained

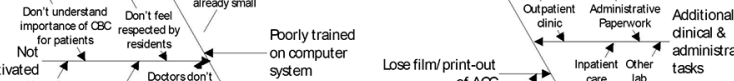

Not on computer lose film/print-out clinical \& Dodorsdon't system Inpatient Other tasks

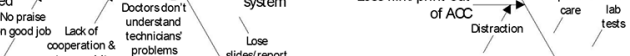

cooperation \& problems
team spirit

bet technicians $\rightarrow$ Negative feelings bet
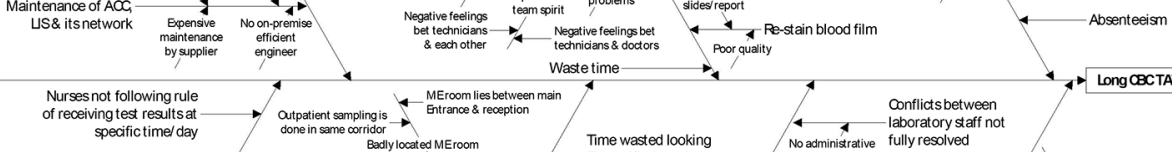

Wastetime $\longrightarrow$

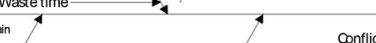

Disputeswith inpatient

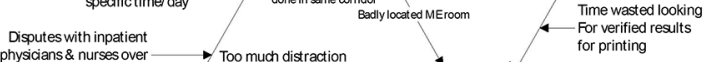
r late CBCrequests by patients \& family No system fo
reporting delayed
resultsto nurses

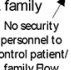

Technicians refer
patientswith any
inty
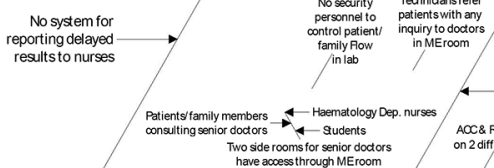

Workin walk long

batches distances

Acc\& \&egistration different Aoc\& engistration process
on 2 different floors steps have acoess through MEroom

More distraction $\longrightarrow$

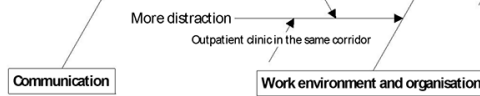

steps Conflicts between - laboratory staff not

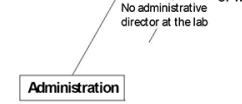


Root causes selected from control-impact matrix in the analyse phase

Haematologist and laboratory management-related

- Separate schedules with overlapping duties

- Haematologists also responsible for inpatient and outpatient clinical care

- No obligation/strict rule to reject requests without a diagnosis

- No specified time and place to answer patient queries outside patient rounds

Laboratory technician-related

- The re-staining process is unorganized and unstandardised

- Technicians unaware of the consequences of poor staining

- Technicians have low skills in preparing stain and staining films

Location/arrangement-related

- Bad ME room location

- Outpatient clinic occupying part of the laboratory opening onto same corridor as ME room because original clinic being renovated

- No distinct haematology inpatient ward for haematologist responsible for inpatient care to be present during the day

Equipment/IT-related

- ACC unable to function properly when connected to LIS network

- No air-conditioning in ACC room

Inpatient physician/nurse-related

- Inpatient physicians unaware of the relevance of patient diagnosis for $\mathrm{ME}$

- Inpatient physicians unaware of the difference in time and effort between tests requiring $\mathrm{ME}$ and those that don't

- Inpatient nurses can receive ACC analysis results by copying them off the manual register without waiting for verified report after ME

- Unregulated sending of late urgent $\mathrm{CBC}$ requests by inpatient physicians after return of phlebotomist back to the laboratory
Remedies selected from prioritization matrix in the improve phase

- Create one organized detailed schedule with no overlap

- Rule set by hospital in collaboration with laboratory management

- Dedicate specified time after outpatient clinic with clear schedule

- Standardise film re-staining process

- Training workshop to improve skills of laboratory technicians and raise awareness

- Assign housekeeper at main laboratory entrance to organize patient flow

- Hasten ongoing renovation of original outpatient clinic which is outside laboratory premises

- Dedicate specified time after outpatient clinic with clear schedule

- Replace ACC with upgraded version with IT involvement to ensure optimal LIS connection

- Air-conditioner fitted in the room

- Meetings to explain importance of documenting diagnoses for ME

- Meetings to raise awareness and agree on ways to request either type of test

- Posters in inpatient wards as reminders

- Manual registration step is eliminated

- Folder with print-outs of ACC worklist kept in lower floor, away from reception so inaccessible to nurses

- Standardise the late urgent $\mathrm{CBC}$ request process
Table A1.

Final list of staffselected root causes and implemented remedies 
IJLSS

13,5

1182

\section{Appendix 3}

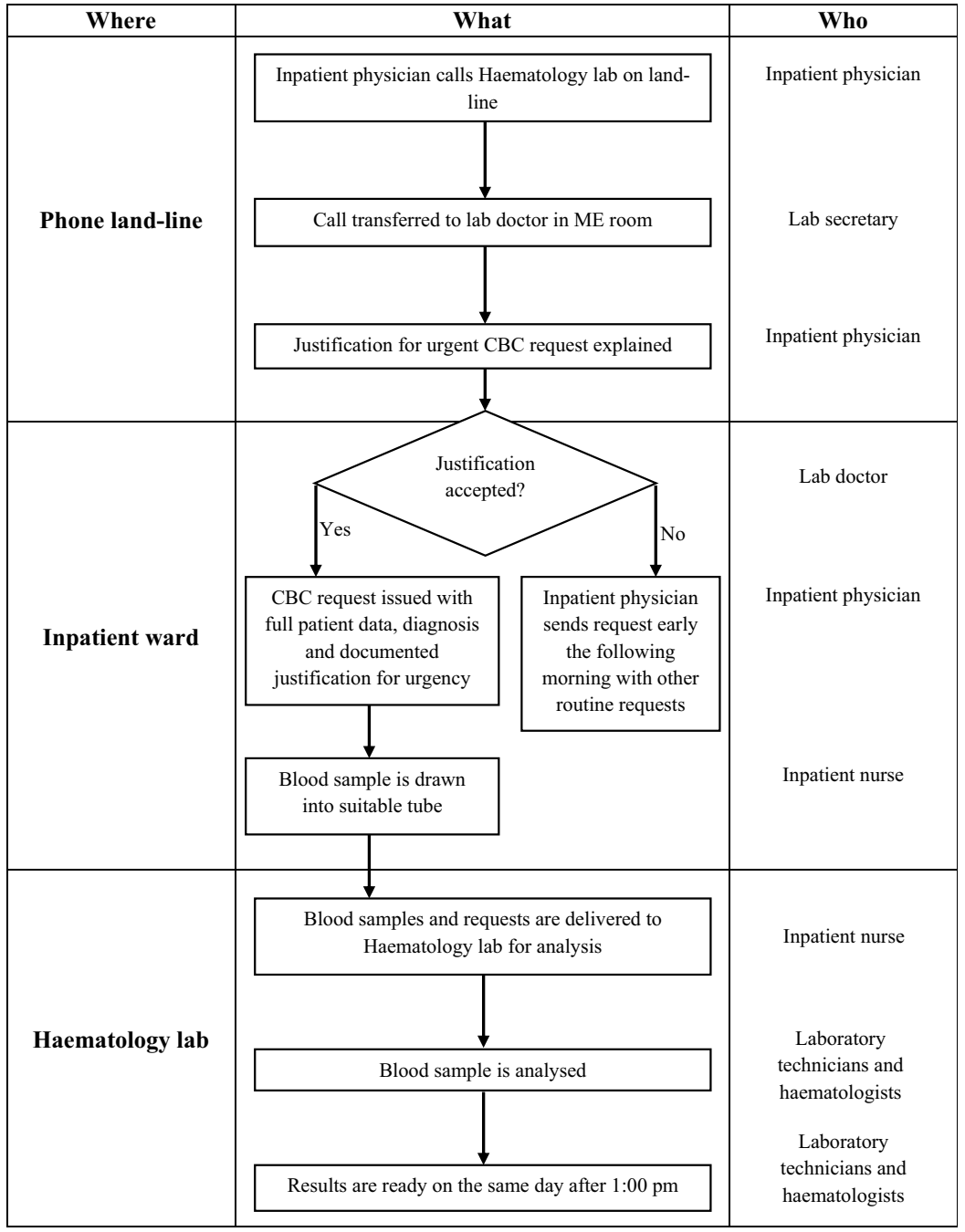

Figure A2.

New standardised process of late $\mathrm{CBC}$ requests

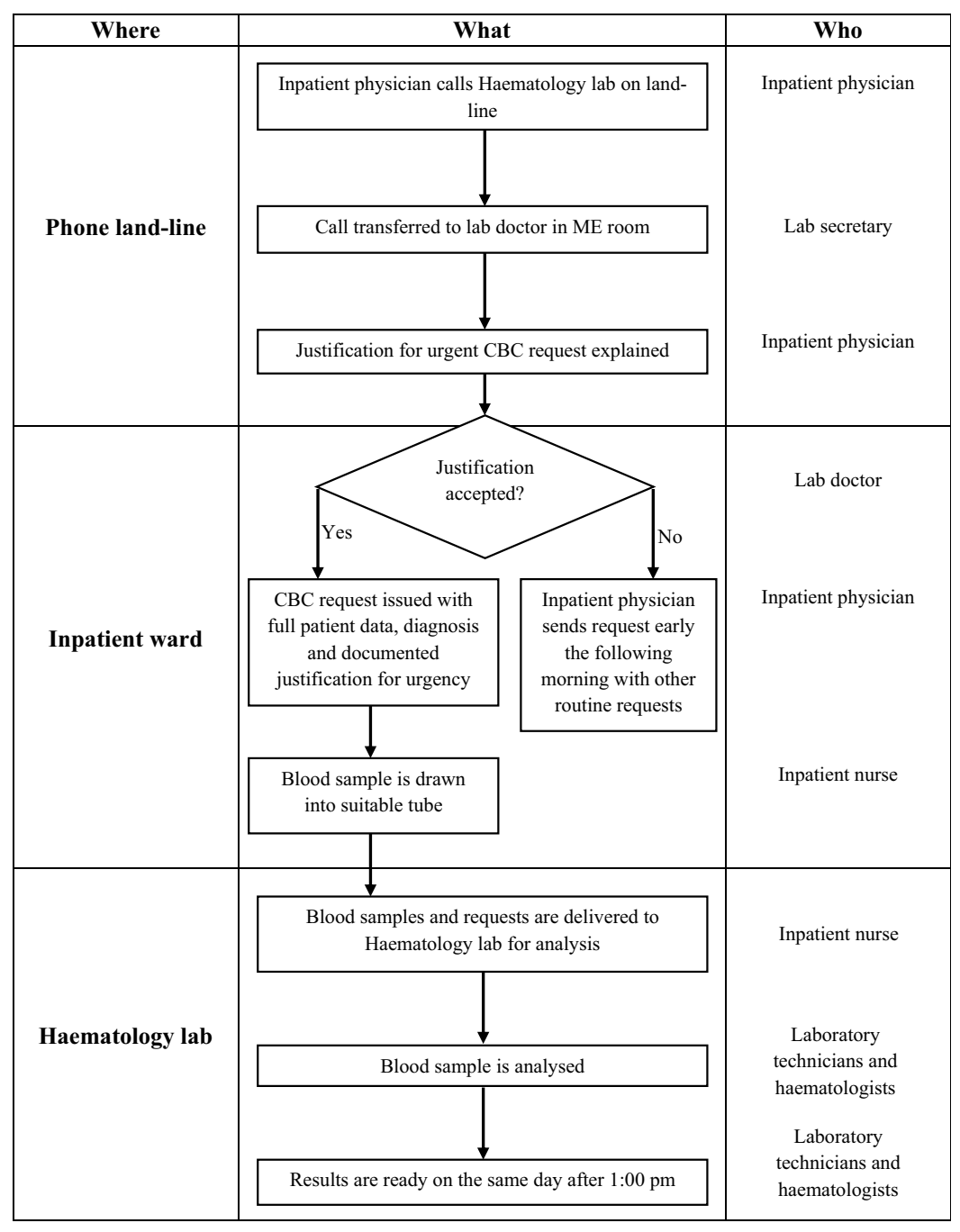




\begin{tabular}{|c|c|c|c|c|c|c|}
\hline \multirow[b]{2}{*}{ Control variable } & \multicolumn{2}{|c|}{ Measurement } & \multirow{2}{*}{$\begin{array}{l}\text { Specification } \\
\text { (USL-LSL) }\end{array}$} & \multicolumn{2}{|c|}{ Action when out of control } & \multirow[b]{3}{*}{1183} \\
\hline & How measured & Who analyzes & & Who acts & What done & \\
\hline $\mathrm{CBC}$ s verified & Verification time & Haematologist & 4 points trending & Senior & Investigate & \\
\hline $\begin{array}{l}\text { the following } \\
\text { morning }\end{array}$ & $\begin{array}{l}\text { selected CBCs } \\
\text { performed each } \\
\text { day for } 1 \text { week } \\
\text { (total } 60 \text { tests) }\end{array}$ & $\begin{array}{l}\text { background } \\
\text { using a } p \text {-chart }\end{array}$ & $\begin{array}{l}\text { above UCL, } 2 \text { of } 3 \\
\text { successive points } \\
\text { above } 2 \text { SD, } 6 \\
\text { points shifting } \\
\text { above the } \\
\text { centerline }\end{array}$ & & delay & \\
\hline ACC errors & $\begin{array}{l}\text { Counting the } \\
\text { number of errors } \\
\text { on ACC daily }\end{array}$ & ACC technician & Zero to 1 per day & $\begin{array}{l}\text { Laboratory } \\
\text { management }\end{array}$ & $\begin{array}{l}\text { Contact ACC } \\
\text { machine } \\
\text { engineers }\end{array}$ & \\
\hline Interruptions & $\begin{array}{l}\text { At least } 2 \\
\text { haematologists } \\
\text { in the ME room } \\
\text { rate distraction } \\
\text { per day on a } \\
\text { scale from } 0 \text { to } 10\end{array}$ & $\begin{array}{l}\text { Laboratory } \\
\text { management }\end{array}$ & Zero to 4 & $\begin{array}{l}\text { Laboratory } \\
\text { management }\end{array}$ & $\begin{array}{l}\text { Check } \\
\text { housekeeper } \\
\text { compliance }\end{array}$ & \\
\hline Re-stained films & $\begin{array}{l}\text { Count blood } \\
\text { films requiring } \\
\text { re-staining per } \\
\text { day }\end{array}$ & Haematologists & Zero to 2 & $\begin{array}{l}\text { Workshop } \\
\text { trainer }\end{array}$ & $\begin{array}{l}\text { - Investigate } \\
\text { - Inspect } \\
\text { - Conduct more } \\
\text { frequent audits }\end{array}$ & \\
\hline $\begin{array}{l}\text { Requests without } \\
\text { diagnosis }\end{array}$ & $\begin{array}{l}\text { Count number of } \\
\text { requests without } \\
\text { a diagnosis per } \\
\text { day }\end{array}$ & Phlebotomists & Zero to 3 & Phlebotomists & $\begin{array}{l}\text { Exclude ANY } \\
\text { such requests } \\
\text { from the days' } \\
\text { work }\end{array}$ & \\
\hline $\begin{array}{l}\text { Laboratory } \\
\text { management }\end{array}$ & $\begin{array}{l}\text { Contact } \\
\text { department head } \\
\text { to investigate } \\
\text { and remind } \\
\text { physicians }\end{array}$ & & & & & $\begin{array}{l}\text { Table A2. } \\
\text { The control plan }\end{array}$ \\
\hline
\end{tabular}

\section{Corresponding author}

Islam Ibrahim can be contacted at: islam.k.ibrahim@outlook.com

For instructions on how to order reprints of this article, please visit our website: 